\title{
LAS ILUSTRACIONES \\ EN LA ENSEÑANZA-APRENDIZAJE DE LAS CIENCIAS. ANÁLISIS DE LIBROS DE TEXTO
}

\author{
PERALES, F. JAVIER ${ }^{1}$ y JIMÉNEZ, JUAN DE DIOS ${ }^{2}$ \\ ${ }^{1}$ Departamento de Didáctica de las Ciencias Experimentales. Facultad de Ciencias de la Educación \\ Universidad de Granada. Campus Universitario de Cartuja. 18071 Granada \\ fperales@ugr.es \\ ${ }^{2}$ Instituto de Educación Secundaria «Cerro de Los Infantes». Pinos Puente (Granada) \\ jjv00361@averroes.cica.es
}

\begin{abstract}
Resumen. Este trabajo centra su atención en la importancia que poseen las ilustraciones que utilizan los libros de texto de ciencias para la comprensión de su contenido. Para ello se parte de una fundamentación teórica en cuanto a los requisitos que deberían cumplir aquéllas para favorecer su adecuado procesamiento, así como la diferente morfología que suelen presentar en los libros de texto. A continuación se aborda un proceso de diseño y validación de una taxonomía para la categorización de las ilustraciones, la cual fue aplicada a los temas de mecánica de una muestra representativa de siete libros de educación secundaria obligatoria y a tres previos. Tras este análisis se discuten los resultados y se extraen unas conclusiones tendentes a la mejora en el uso de las ilustraciones.

Palabras clave. Didáctica de la física, educación secundaria, libros de texto, ilustraciones, taxonomía.
\end{abstract}

Summary. This paper focuses on how important the illustrations in science textbooks can be for understanding their content. To that end we start from a theoretical base of the requirements that those illustrations should accomplish to favour their appropriate processing, as well as from the different morphology that they normally show in textbooks. Then we approach a process of design and validation of a taxonomy to categorize the illustrations that was applied to the subject of Mechanics on a representative sample of seven textbooks of Obligatory Secondary Education (ESO) and three books from a system previous to ESO. After this analysis we discuss the results and draw conclusions aimed at improving the use of illustrations.

Keywords. Physics education, secondary education, textbooks, illustrations, taxonomy.

\section{INTRODUCCIÓN}

Uno de los pilares básicos sobre los que se sustenta la acción docente, en cualquier nivel educativo, es el libro de texto. Resulta hoy por hoy incuestionable su poderosa influencia en el trabajo de aula, tanto para los profesores como para los alumnos, constituyéndose en bastantes ocasiones como el referente exclusivo del saber científico. Pero los libros de texto son también una mercancía para las empresas editoriales que compiten entre sí para dominar el mercado.

Esta serie de condicionantes, entre otros, convierten el proceso de selección de libros de texto en un acto con serias repercusiones educativas y económicas. Ahora bien, ¿de qué criterios disponen los profesores para seleccionar los libros de texto?
A pesar de que las ilustraciones ocupan en los libros de texto de educación primaria y secundaria en torno a un $50 \%$ de superficie y de que resultan relativamente frecuentes en el ámbito pedagógico y editorial las guías de revisión de libros de texto, la importancia que se le concede al papel de las ilustraciones resulta casi anecdótica. Por ejemplo, en un documento relativo al establecimiento de pautas para la elaboración de materiales curriculares sólo se dedican 3 ítems, de un total de 150, al papel que deben jugar las ilustraciones (Parcerisa, 1996).

En el ámbito específico de los libros de ciencias también resultan habituales los estudios de análisis del contenido y de errores conceptuales presentes en aquéllos, quedando prácticamente al margen las ilustraciones correspon- 
dientes o, cuando se hace, se consideran exclusivamente en relación con algún contenido específico (Pérez de Eulate, 1999). En segundo lugar, consideramos que un freno al estudio de las imágenes procede de su propia naturaleza. Podemos declararnos partidarios o contrarios a determinada formulación de las leyes de Newton en un texto escolar, o respecto a la secuencia didáctica utilizada para introducirlas, pero es más difícil decidir si el diseño gráfico de la página, con las imágenes que contiene, resulta oportuno para los propósitos del material examinado. Esta dificultad se incrementa cuando deseamos realizar una valoración general de la estrategia seguida en la ilustración de un texto completo o de un tema en particular.

El propósito de este trabajo consiste en presentar unas bases teóricas sobre las que evaluar la adecuación de las ilustraciones en los libros de ciencias para, a continuación, proponer una taxonomía y una metodología de análisis. Finalmente se describen los resultados de su aplicación a una muestra de libros de física y química de $4^{\circ}$ curso de ESO y se extraen algunas consecuencias para la enseñanza y el diseño gráfico.

Aunque reconocemos la importancia de la comprensión del texto escrito por parte del lector (Campanario y Otero, 2000) para indagar de un modo global en las posibilidades didácticas del libro de texto, estimamos que la dimensión icónica es de la suficiente relevancia para dedicarle en exclusiva una línea de investigación como la que aquí presentamos.

\section{MARCO TEÓRICO}

Analizar las ilustraciones que encontramos en los manuales de física y química supone considerar sus aspectos formales y semánticos. Los aspectos formales se refieren a cómo están realizadas y dispuestas las ilustraciones en el texto, mientras que los semánticos se refieren a qué significado poseen para el lector.

Se podría pensar que el análisis formal sólo interesa al grafista o al editor, mientras que el análisis semántico correspondería al profesor o al investigador en didáctica de las ciencias; sin embargo, los resultados de las investigaciones publicadas muestran que difícilmente se pueden desligar ambas dimensiones y es imprescindible contemplarlas en su conjunto.

El análisis formal puede realizarse sobre las características particulares de cada ilustración o atendiendo también a la relación entre el texto y las ilustraciones.

En cuanto al primer aspecto, la corrección formal dependerá del cumplimiento de un conjunto universal de convenciones gráficas (Durán, 1987; Winn y Solomon, 1991; Winn, 1994) que facilitan la lectura de las imágenes. Estas convenciones incluyen reglas como el buen uso de la perspectiva, el orden y la dirección habitual de lectura, el uso adecuado del color, etc.
Pero en los manuales escolares no se encuentran ilustraciones aisladas sino textos con multitud de ellas intercaladas. Si esperamos de las ilustraciones que ayuden a comprender el texto debemos estudiar dónde aparecen y qué relaciones mutuas se establecen, es decir, se han de considerar los problemas de compaginación, la inclusión de textos específicos junto a las imágenes o el uso de textos dentro de la imagen -etiquetas verbales-. También será objeto de análisis considerar qué pasajes del texto han sido ilustrados y su finalidad.

Puede comprenderse, pues, que la naturaleza de la investigación que nos ocupa posee un claro carácter interdisciplinar en cuanto puede ser abordado desde ópticas muy dispares: semiótica, diseño gráfico, publicidad, psicología, etc. Evidentemente este hecho desborda las posibilidades de una investigación como la que aquí se expone, por lo que nos vamos a centrar en las contribuciones más reseñables en el marco de la psicología y en el de otras investigaciones empíricas.

Resulta evidente que para la psicología no existe ilustración sino observador, en la medida que es éste el que le dota de significado (Deforge, 1991).

La larga tradición histórica de esta disciplina desde que se hallara diluida en la filosofía griega ha asistido a distintos énfasis concedidos al papel de las imágenes mentales en el pensamiento. Así, Aristóteles admitía la existencia de un pensamiento con imágenes o, en un pasado mucho más reciente, Bruner y sus colaboradores (1956) consideran como uno de los tres sistemas de representación en el pensamiento, el icónico. También debe destacarse el estatus asignado por Piaget al pensamiento figurativo en cuanto a poseer una capacidad transformadora y anticipatoria (Piaget, 1980).

Fue, no obstante, la psicología de la Gestalt la que concedió por vez primera, a la percepción, una dimensión sustantiva en la adquisición de conocimiento al destacar el papel consciente de las personas en la organización de la percepción. La Gestalt aportó reglas útiles, vigentes aún en la teoría del diseño gráfico (Dondis, 1980), para mejorar los procesos de interpretación de las imágenes. En concreto, el concepto de pregnancia (prägnanz en alemán) -«buena forma»-da cuenta de los requisitos derivados de un principio de organización de la percepción, que podría enunciarse diciendo que «todo objeto que sea percibido lo hará adoptando la forma más simple posible». Esta regla general se concreta en leyes empíricas respecto a cómo los sujetos perciben las imágenes (Swenson, 1984; Winn, 1994).

Estos principios derivados de la Gestalt y afianzados en la práctica del diseño gráfico son muy valiosos a la hora de analizar una ilustración concreta desde la perspectiva de su hipotética legibilidad. En la práctica supone disponer de normas que permitan optimizar una imagen de cara a su utilidad para la comunicación. Entre ellas destacamos la recomendación de utilizar ilustraciones que faciliten la percepción de las formas significativas en detrimento de los aspectos secundarios de la imagen. 
Si la aportación más significativa de la Gestalt consistió en rechazar que el conocimiento humano era una simple «impresión» en la memoria del mundo exterior, como postulaban las teorías asociacionistas, el papel activo del sujeto en la comprensión se destaca en la noción de modelo mental propuesta por Johnson-Laird (1980).

El término modelo mental se refiere a una representación mental elaborada por las personas cuando interaccionan con su medio, textos, imágenes o combinaciones entre ambos. Los modelos mentales incluyen datos procedentes del exterior, conocimientos previos y expectativas del sujeto, etc., dando lugar a representaciones dinámicas en la memoria de trabajo.

Ahora bien, ¿cómo se coordina entre sí la información verbal y espacial que llega a un sujeto? Está asumido que existen diferentes sistemas cognitivos especializados en el procesamiento de la información verbal y no verbal. La activación de uno u otro sistema vendría determinada por la tarea concreta impuesta al lector (Zimmer, 1994). Desde esta perspectiva, la inclusión de imágenes en los libros de texto vendría justificada por su idoneidad para suministrar información espacial. No obstante, esto no significa que no sea posible describir verbalmente la información espacial para facilitar un modelo mental. Pero, al mismo tiempo, existen evidencias de que la información no espacial puede representarse mentalmente en el sistema de memoria espacial (Glenberg y Langston, 1992). Estos autores sugieren que las ilustraciones favorecen en los lectores la construcción de un modelo mental mientras leen, contribuyendo a mejorar la comprensión del texto. Así pues, la comprensión y la memorización a largo plazo estarían determinados parcialmente por el texto, la ilustración y las inferencias generadas por el individuo a través del modelo mental construido durante la lectura, que incluiría también los conocimientos previos del lector activados a lo largo de ésta.

La distinción entre dos subsistemas cognitivos especializados en el procesamiento de la información verbal y no verbal se encuentra recogida especialmente en la teoría de la doble codificación de Paivio (1986). Destacamos entre otros a este autor por su influencia en las investigaciones que nos ocupan.

Tras esta breve introducción podemos preguntarnos: ¿Realmente es posible afirmar que las imágenes facilitan siempre la comprensión y memorización de la información? Parece suficientemente contrastado que el modo de procesamiento de la información contenida en las imágenes representa ciertas ventajas frente a la lectura de textos, ya que permite una lectura en superficie, es decir, no está limitada por la lectura secuencial característica del lenguaje verbal (Moles, 1991). Por el contrario, la imagen se caracteriza además por su polisemia, de modo que resulta muy difícil predecir cuál va a ser la interpretación que sobre una ilustración va a realizar una persona. Esta especificidad de la imagen, como instrumento de comunicación abierto o ambiguo, plantea un problema educativo de primer orden que afecta a los editores, a los profesores que lo usan y al propio alumno.
Estas dificultades han hecho que la investigación -especialmente en el ámbito psicológico- se haya visto dificultada y necesitada de metaanálisis, como el efectuado por Levie y Lentz (1982) sobre cincuenta y cinco trabajos previos, cuyos resultados más destacables son:

1) En las situaciones habituales en las que se desarrolla la educación, la introducción de ilustraciones que embellecen el texto no mejora el aprendizaje de la información contenida, aunque en principio los lectores se sientan atraídos por ellas.

2) Cuando las ilustraciones redundan la información contenida en el texto, se produce un efecto positivo sobre el aprendizaje.

3) La presencia de ilustraciones no facilita ni dificulta el aprendizaje de la información no ilustrada, es decir, la ayuda prestada por las ilustraciones es específica de la información que contienen.

4) Las ilustraciones adecuadas ayudan a comprender el texto ilustrado, facilitan su memorización, especialmente a largo plazo, y permiten una gran variedad de funciones instructivas. Algunos autores proponen que las ilustraciones facilitan el aprendizaje aportando un contexto en el que se organiza la información contenida en el texto.

5) En algunas ocasiones, las ilustraciones pueden sustituir muy bien a las palabras aportando con mayor eficacia información extralingüística.

6) Los lectores tienen dificultad para comprender las ilustraciones complejas si no se les ayuda a la hora de leerlas. Muy a menudo los lectores observan superficialmente las ilustraciones sin esperar de ellas información relevante.

7) Las ilustraciones provocan reacciones afectivas y hacen más atractivos los documentos.

8) Las investigaciones en las que se ha incentivado a los alumnos a crear sus propias imágenes mentales, o incluso sus propios dibujos, muestran resultados positivos en algunos casos pero con complejas interacciones. En general, los niños más pequeños se benefician más de las ilustraciones que de estas ayudas.

Como resumen, los autores manifiestan que las ilustraciones mejoran el recuerdo y facilitan la comprensión de textos en los que se describen las relaciones entre diversos elementos siempre que aquéllas muestren esas relaciones. Ahora bien, cuando son complejas, requieren una ayuda suplementaria para poder interpretarlas y beneficiarse de ellas.

No podemos tampoco ignorar otros roles significativos jugados por la imagen estática en el ámbito de la enseñanza de las ciencias (Aster, 1996). Por citar algunos, se ha identificado mediante análisis de tebeos la imagen de la ciencia (Gallego et al., 2001), se ha enseñando con caricaturas cómicas (Worner y Romero, 1998) o viñetas 
conceptuales (Keogh y Naylor, 1998), se han analizado las ilustraciones elaboradas por los estudiantes a partir de muestras microscópicas (Díaz de Bustamente y Jiménez, 1996), se ha inducido a los estudiantes a modelizar a través de viñetas de tebeos (Gutiérrez, 1994) o se han utilizado en pruebas de diagnóstico de las ideas previas de los alumnos, por ejemplo, las interview-about-instances, de Osborne y Gilbert (1980).

\section{Funciones desempeñadas por las ilustraciones en los textos escolares y su diversa morfología}

Las ilustraciones se incluyen en los libros de texto con diversas finalidades. Si se revisan las diversas clasificaciones hechas al respecto por distintos autores (Bernad, 1976; Duchastel, 1981; Levin et al., 1987; Feschotte y Moles, 1991; Gillespie, 1993), se pueden extraer las siguientes funciones en común:

- Decorar los libros, es decir, hacerlos más atractivos para despertar el interés de los lectores.

- Describir situaciones o fenómenos basándose en la capacidad humana de procesar la información visual (Larkin y Simon, 1987; Feschotte y Moles, 1991) y su ventaja frente a los textos escritos en la estimulación de modelos mentales (Stone y Golk, 1981; Duchastel, 1981).

- Explicar las situaciones descritas. Esto es, en este caso las ilustraciones no sólo muestran el mundo sino que lo transforman con la intención de evidenciar relaciones o ideas no evidentes por sí mismas, a fin de facilitar su comprensión por parte del lector.

Estas dos últimas funciones han promovido diversos trabajos (Levie y Lentz, 1982; Larkin y Simon, 1987; Mayer y Gallini, 1990; Chen, 1995) que coinciden en señalar que las ilustraciones desempeñan un papel crítico en las tareas de resolución de problemas, ya que muestran relaciones estructurales con claridad y economía.

Weidenmann (1994) clasifica las ilustraciones de los libros de texto en dos grupos: a) las que poseen un formato pictórico o descriptivo (depicting features); y b) las que se alejan de la realidad y usan códigos simbólicos (directing features). Esta distinción también la realizan Deforge (1991) y Winn (1994) en términos parecidos. Las ilustraciones del primer grupo poseen como finalidad la percepción del contenido imitando la realidad, mientras que las del segundo se emplean para facilitar la comprensión usando argumentos visuales que se alejan de la imitación de lo real. A partir de ahora las denominaremos figurativas y no figurativas, respectivamente. Los medios que emplean unas y otras son diferentes: las primeras se apoyan en los contornos, los sombreados, la perspectiva, etc.; y las segundas emplean los contrastes, signos especiales o composiciones en las que se resaltan las relaciones entre los elementos. Por consiguiente, las ilustraciones figurativas demandan del lector la atención y el conocimiento de los códigos clásicos del dibujo realista, mientras que las no-figurativas exigen un mayor esfuerzo para interpretar las intenciones del autor. Son éstas, por lo tanto, las que suelen plantear problemas a los lectores, puesto que existe la posibilidad de que sean presentadas como si se trataran de analogías del mundo real, propiciando aprendizajes no deseados (Mokros y Tinker, 1987).

El grado en que una imagen se asemeja al objeto del mundo real representado por ella puede expresarse mediante el concepto de iconicidad desarrollado por Feschotte y Moles (1991).

\section{El procesamiento de las ilustraciones}

Establecido ya que las ilustraciones pueden ejercer diferentes funciones en los libros de texto y que su morfología puede ser igualmente variada, nos interesa resaltar el papel de las ilustraciones en promover la comprensión. Las investigaciones que aquí se ubican se plantean como objetivo fundamental explicar por qué determinadas imágenes facilitan la comprensión y cuáles son las condiciones particulares para que ésta se favorezca.

Como se expuso anteriormente, desde diversos enfoques se considera que las imágenes promueven modelos mentales (Johnson-Laird, 1983). Pero no debe identificarse un modelo mental con una simple «copia» mental de las imágenes. Los trabajos de Glenberg y Langston (1992) o los de Robinson y Kennet (1995) sobre el uso de los gráficos para representar información verbal no espacial muestran que los lectores pueden beneficiarse de las imágenes incluidas en un texto para mejorar su comprensión de las relaciones entre los conceptos, incluso si éstos carecen de propiedades espaciales. No obstante, también se encuentran investigaciones con resultados contradictorios respecto a si las imágenes incluidas en un texto favorecen la producción de modelos mentales (Gyselinck y Tardieu, 1994).

Dentro de las investigaciones promovidas para mejorar la utilización de las imágenes en la comprensión de textos destaca el estudio de la coordinación entre el texto y la imagen (Mayer, 1989; Mayer y Gallini, 1990; Mayer, 1994; Mayer et al., 1996). Estos autores encuentran que, para que una imagen pueda ayudar a los lectores, se han de cumplir las siguientes condiciones: a) los textos que más se benefician de las ilustraciones son los explicativos, es decir, que contienen pasajes en los que se describen en términos causales las relaciones entre las partes que constituyen un conjunto; $b$ ) que los lectores no posean conocimientos específicos sobre el tema -en caso contrario, la preexistencia de un modelo mental adecuado hace superfluas las imágenes-; y c) que el texto sea lo suficientemente complejo para que la construcción del modelo mental del mismo requiera esfuerzo y ayuda.

No obstante, aun en estas condiciones, las imágenes favorecen el aprendizaje de un modo selectivo, fundamentalmente en el recuerdo explicativo y en la resolución de problemas.

Por otra parte, distintos autores coinciden en la necesidad de dirigir la atención de los lectores para evitar una 
lectura superficial de las imágenes (Maichle, 1994; Peek, 1994) mediante instrucciones específicas y el uso de determinadas tareas a partir de la lectura de las imágenes (extrapolación de la información, establecimiento de comparaciones, análisis de datos, resolución de problemas...) (Gillespie, 1993). Otro autor (Reinking, 1986) propone el uso de estrategias basadas en el establecimiento de conexiones entre el conocimiento previo de cada alumno, el texto y la ilustración.

Globalmente se puede afirmar que existen suficientes evidencias de que es necesario dirigir, mediante palabras o tareas específicas, la lectura de las imágenes para optimizar sus efectos positivos sobre el aprendizaje.

Finalmente, cabe hacer una última referencia a las diferencias individuales a la hora de procesar la información gráfica.

Existen evidencias empíricas de que todas las personas no poseen las mismas capacidades para utilizar la información gráfica. Citamos algunos ejemplos:

- Maichle (1994) da cuenta de las diferencias significativas entre individuos en la interpretación de gráficas bidimensionales (velocidad-tiempo, presión-volumen, etc.).

- McDaniel y Waddil (1994) investigaron los efectos de los dibujos sobre la comprensión y la memorización en alumnos de diferente capacidad de comprensión lectora. Los resultados apuntan a que los lectores con mayor habilidad de comprensión de las imágenes se benefician de la ilustración en su conjunto, mientras que los que muestran una peor habilidad fijaban su atención en los detalles de la figura. Extraen la consecuencia de que, en contra de una opinión muy generalizada, las imágenes no suponen necesariamente una ayuda compensatoria para los alumnos menos capacitados cognitivamente.

- Schnotz y sus colaboradores (1993) muestran, en un estudio en el que se suministraba a los lectores un hipertexto con imágenes, que la estrategia empleada en la interpretación de la imagen influye en su aprendizaje. Concretamente obtuvieron mejores resultados los que usaron con mayor intensidad la ilustración y fueron capaces de construir un modelo mental adecuado. Como consecuencia para la enseñanza proponen que se entrene a los alumnos a usar adecuadamente los gráficos. En este sentido, también encontramos que la habilidad espacial, un clásico factor integrante de la inteligencia al cual se ha atribuido con frecuencia un origen innato (Ausubel, 1982, p. 266; Woolfolk y McCune, 1986, pp. 480-482), puede mejorarse significativamente mediante una estrategia destinada a desarrollar la interiorización de determinadas transformaciones (Seel y Dörr, 1994).

Para terminar quisiéramos plantear algunas reflexiones respecto a uno de los usos más frecuentes de las imágenes en los libros de ciencias: las analogías. Las analogías se establecen cuando dos situaciones o sistemas pueden considerarse estructuralmente semejantes y una de ellas es conocida y comprendida por los alumnos. A esta situación se la denomina dominio fuente, mientras que a la situación que se quiere transmitir se le denomina dominio destino. En general, los modelos analógicos se presentan como ayudas compensatorias para el alumnado con más dificultades. No obstante, la inadecuación de algunas analogías gráficas que se emplean en los textos escolares ha sido señalada por Giordan y Vecchi (1988) o por Shipstone y sus colaboradores (1988). Como se comentaba antes respecto al trabajo de McDaniel y Waddill (1994), si los lectores con menos habilidad no extraen los aspectos esenciales o estructurales del texto, es razonable suponer que tengan dificultades para establecer una analogía en tanto que distraen su atención sobre los elementos anecdóticos o parásitos de las representaciones pictóricas. Coinciden con esta apreciación Alexander y Kulikowich (1994) al plantear que muchas de las analogías presentes en los textos escolares de física elevan las demandas cognitivas en lugar de rebajarlas.

\section{ANÁLISIS DE LAS ILUSTRACIONES CON- TENIDAS EN LOS LIBROS DE TEXTO DE CIENCIAS EXPERIMENTALES. ELABORA- CION DE UNA TAXONOMIA}

De acuerdo con los objetivos de este trabajo expuestos en la introducción, se inició este análisis mediante una categorización de las ilustraciones presentes en libros de texto españoles surgidos a partir de la reciente reforma del sistema educativo y, en concreto, en los temas que abordan la mecánica elemental.

La elección de esta temática tiene su origen en el hecho de que las dificultades de aprendizaje del concepto de fuerza están bastante bien investigadas (Pfundt y Duit, 1994) desde diversos enfoques que suministran pautas para evaluar la adecuación de las imágenes incluidas en los libros de texto. Asimismo, la utilización de un código simbólico como es la notación vectorial, adicionado o intercalado entre dibujos figurativos, expone con claridad la problemática de la superposición de diferentes códigos icónicos y su posible influencia en la enseñanza. Más concretamente, la introducción de la notación vectorial ilustra a la perfección uno de los problemas más frecuentes en la enseñanza de la ciencia: la confusión entre significado y significante. Dicho en otras palabras, podría ocurrir que la representación vectorial de fuerzas haya pasado de ser un instrumento de aprendizaje a un objetivo de la enseñanza en sí mismo.

Finalmente, siendo la mecánica elemental un contenido curricular muy tradicional, esperábamos encontrar pocas diferencias en su presentación por parte de los libros de los diferentes autores, por lo que sería previsible que las diferencias radicaran en la propia secuencia didáctica y en su tratamiento gráfico.

\section{Procedimiento de elaboración y validación de la taxo- nomía}

La elaboración de un instrumento de análisis debe partir de los objetivos que la investigación pretende cubrir. En 
nuestro caso deseábamos describir en qué medida los ilustradores gráficos habían tenido en cuenta los resultados de la investigación respecto a cómo mejorar la comprensión de las imágenes y qué uso se hacía de éstas en el conjunto de la planificación didáctica de los libros.

En una primera fase se estudiaron un total de 727 ilustraciones de nueve libros de $4^{\circ}$ curso de educación secundaria obligatoria. En este estudio se incluyeron variables que describían aspectos formales de las ilustraciones y la función que desempeñaban en el texto. Para esta última variable se utilizó una rejilla abierta, lo que se denomina clasificación por montones (Zuleima, 1991), de modo que, cuando aparecía una función no descrita anteriormente y que no pudiera asimilarse a ninguna de las existentes, se añadía a la lista. Este procedimiento es habitual cuando no se dispone de datos previos e interesa describir la situación (Weil-Barais y Corrover, 1993). A la luz de los resultados obtenidos (Jiménez y Perales, 1997), se discutieron las categorías utilizadas dentro de un grupo de trabajo formado por el investigador principal y cuatro profesores de educación secundaria en activo.

Como consecuencia de ello se redujo el número de funciones atribuidas a las ilustraciones dejando sólo las que superaban una frecuencia relativa del $5 \%$.

Para la validación de la estabilidad y reproducibilidad de la taxonomía se empleó el estadístico «Kappa» (Fleis y Cohen, 1969) utilizado por Eltinge y Roberts (1993) en su estudio sobre libros de texto de ciencias. Dicho estadístico proporciona una medida del acuerdo entre dos observadores, corrigiendo la influencia del azar. Kappa posee un rango de 0 a 1 ; los valores próximos a
0 indican una baja fiabilidad y 1 , una fiabilidad alta. En todas las variables, salvo una, el coeficiente Kappa superó el valor de 0,8 .

Finalmente las variables objeto de análisis quedaron como se expone en el cuadro I.

Vamos a describirlas a continuación:

1) Función de la secuencia didáctica en la que aparece la ilustración

Entendemos por secuencia didáctica la serie de afirmaciones, referencias, problemas planteados por los autores del texto, etc., a lo largo del mismo. Asumimos que los textos se elaboran bajo la premisa de que van a ser leídos secuencialmente por los lectores, es decir, el orden de la exposición obedece a un plan establecido para hacer posible el aprendizaje. La secuencia didáctica puede ser fragmentada en unidades elementales a las que denominaremos de aquí en adelante USD (Tabla I).

Para describir la función atribuida por los autores de los libros a las ilustraciones se fragmentaron los textos y se registró qué pasajes del texto habían sido ilustrados y cuáles no. La estructura de las secuencias didácticas de los libros fue analizada por un procedimiento original derivado del campo de la observación de la interacción (Jiménez, 1998; Jiménez y Perales, 2001).

La aplicación y la interpretación son en ocasiones muy similares y se distinguen por su posición en el texto y por su complejidad. La aplicación aclara un concepto o ejercita un procedimiento definido previamente, mientras que la interpretación relaciona varios conceptos.

\begin{tabular}{|l|l|}
\hline $\begin{array}{l}\text { 1) Función de la secuencia didáctica en la que } \\
\text { aparecen las ilustraciones }\end{array}$ & $\begin{array}{l}\text { Para qué se emplean las imágenes, en qué } \\
\text { pasajes del texto se sitúan, etc. }\end{array}$ \\
\hline 2) Iconicidad & Qué grado de complejidad poseen las imágenes \\
\hline 3) Funcionalidad & Qué se puede hacer con las imágenes \\
\hline 4) Relación con el texto principal & $\begin{array}{l}\text { Referencias mutuas entre texto e imagen. } \\
\text { Ayudas para la interpretación }\end{array}$ \\
\hline 5) Etiquetas verbales & \begin{tabular}{l} 
Textos incluidos dentro de las ilustraciones \\
\hline 6) Contenido científico que las sustenta
\end{tabular} \\
\hline
\end{tabular}


Tabla I

Categorías establecidas en la función de la secuencia didáctica en la que aparece la ilustración.

\begin{tabular}{|c|l|}
\hline Nombre & \multicolumn{1}{c|}{ Descripción } \\
\hline Evocación & $\begin{array}{l}\text { Se hace referencia a un hecho de la experiencia cotidiana o concepto que se supone conocido por el alumno. } \\
\text { Ejemplo: «sobre el hielo es muy difícil caminar...». }\end{array}$ \\
\hline Definición & $\begin{array}{l}\text { Se establece el significado de un término nuevo en su contexto teórico. Ejemplo: «cuando la suma de todas } \\
\text { las fuerzas que actúan sobre un cuerpo es cero, éste se mantiene en equilibrio, lo que no quiere decir que esté } \\
\text { en reposo». }\end{array}$ \\
\hline Aplicación & $\begin{array}{l}\text { Es un ejemplo que extiende o consolida una definición. Ejemplo: «cuando arrastramos una silla, estamos } \\
\text { ejerciendo una fuerza». }\end{array}$ \\
\hline Descripción & $\begin{array}{l}\text { Se refiere a hechos o sucesos no cotidianos que se suponen desconocidos por el lector y que permiten aportar } \\
\text { un contexto necesario. También se incluyen en esta categoría conceptos necesarios para el discurso principal } \\
\text { pero que no pertenecen al núcleo conceptual. Ejemplo: «cuando un conductor aprecia un obstáculo sobre } \\
\text { la carretera, no puede detener su vehículo de forma instantánea... distinguimos entre el tiempo de reacción } \\
\text { y el tiempo de frenado». }\end{array}$ \\
\hline Interpretación & $\begin{array}{l}\text { Son pasajes explicativos en los que se utilizan los conceptos teóricos para describir las relaciones entre } \\
\text { acontecimientos experimentales. Ejemplo: «en la mayor parte del camino, la velocidad se mantiene constan- } \\
\text { te, por lo que la fuerza resultante es cero». }\end{array}$ \\
\hline Problematización & $\begin{array}{l}\text { Se plantean interrogantes no retóricos que no pueden resolverse con los conceptos ya definidos. Su finalidad } \\
\text { es incitar a los alumnos a poner a prueba sus ideas o estimular el interés por el tema presentando problemas } \\
\text { que posteriormente justifican una interpretación o un nuevo enfoque. Laimportancia de este tipo de actividad } \\
\text { ha sido destacada por Ogborn (1996) en lo que llama creación de diferencias entre el pensamiento de los } \\
\text { alumnos y las ideas que se quieren introducir. }\end{array}$ \\
\hline
\end{tabular}

\section{2) Grado de iconicidad}

Es una adaptación de la escala de iconicidad de Moles (1991) y establece un grado creciente de simbolización. Categorías:

Las imágenes de menor grado de iconicidad - menos - Fotografía (Fig. 1) realistas- exigen un mayor conocimiento del código simbólico utilizado.

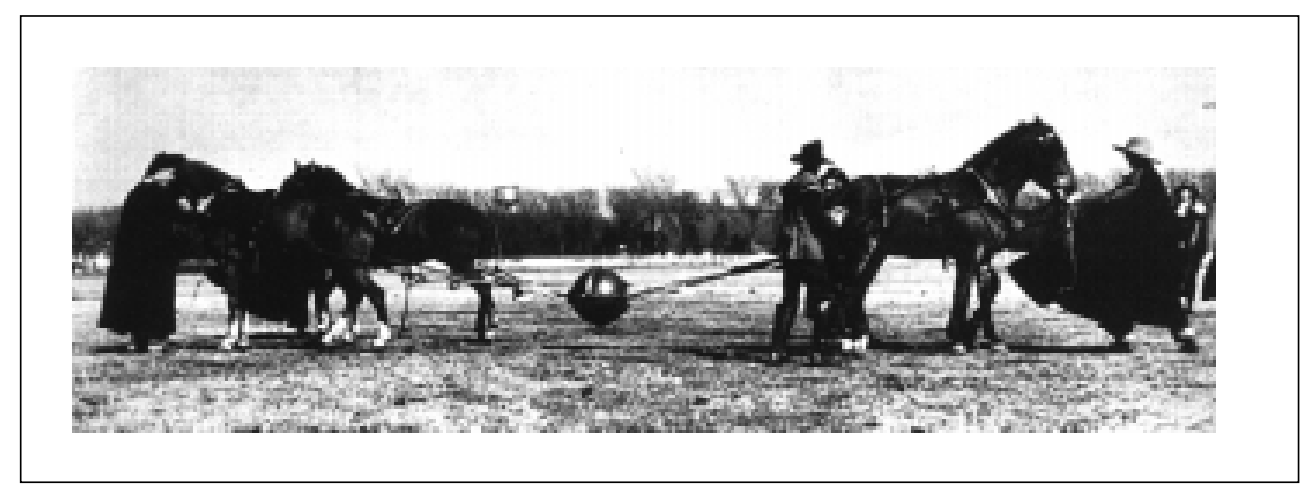


- Dibujo figurativo: Prima la representación orgánica, mostrando los objetos mediante la imitación de la realidad (Fig. 2).

Figura 2

Ejemplo de dibujo figurativo.

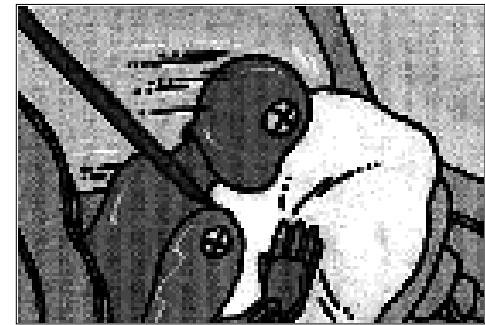

- Dibujo figurativo + signos: Representan acciones o magnitudes inobservables en un espacio de representación heterogéneo (Fig. 3).

Figura 3

Ejemplo de dibujo figurativo + signos.

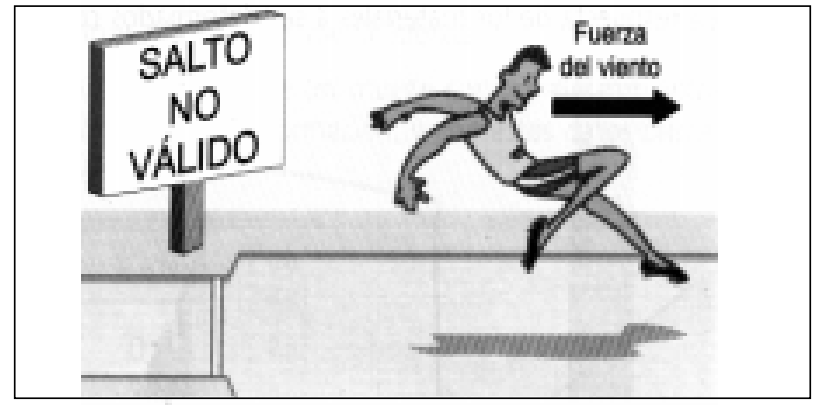

- Como una variante de esta categoría se incluye la figurativa / signos normalizados, que incluye aquellas ilustraciones en las que se representa figurativamente una situación y a su lado se representan algunos aspectos relevantes mediante signos normalizados (Fig. 4).

Figura 4

Ejemplo de ilustración figurativa / signos normalizados.

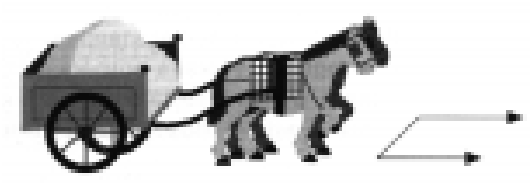

- Dibujo esquemático: Prima la representación de las relaciones prescindiendo de los detalles (Fig. 5).

Figura 5

Ejemplo de dibujo esquemático.

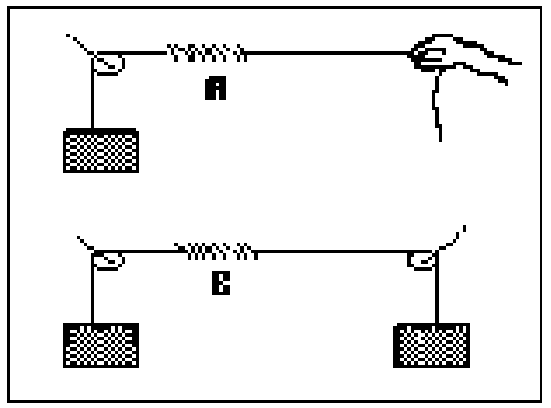

- Dibujo esquemático + signos: Representan acciones o magnitudes inobservables (Fig. 6).

Figura 6

Ejemplo de dibujo esquemático + signos.

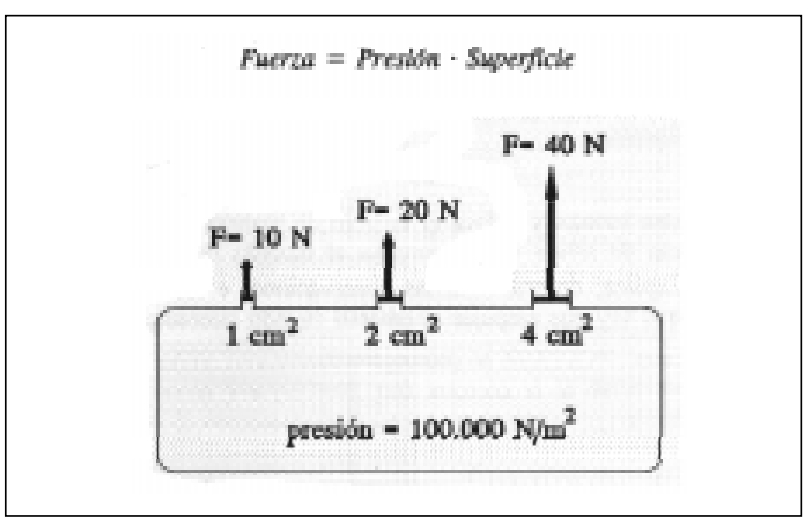

- Descripción en signos normalizados: Constituye un espacio de representación homogéneo y simbólico que posee reglas sintácticas específicas (Fig. 7).

Figura 7

Ejemplo de descripción en signos normalizados.

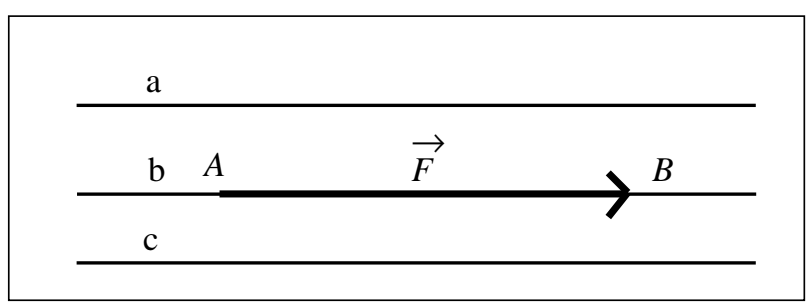

ENSEÑANZA DE LAS CIENCIAS, 2002, 20 (3) 


\section{3) Funcionalidad de las ilustraciones}

La utilización, consciente o inconsciente, de las herramientas gráficas como expresión de ideas suele ser algo habitual, tanto en las actividades de enseñanzaaprendizaje de las ciencias como en los textos representativos del contenido científico. Las aulas suelen ser un escenario donde el profesor hace uso de esta diversidad de medios de expresión, tales como croquis a mano alzada, representaciones de conceptos mediante símbolos analógicos o arbitrarios, símbolos cuantificadores como los vectores, acotaciones, ángulos, etc. o la representación gráfica de funciones. Sin embargo, tanto las ilustraciones utilizadas por el profesor como las incorporadas en los libros de texto suelen requerir de una «alfabetización gráfica» por parte de los alumnos.

La valoración de la mayor o menor funcionalidad de estas herramientas expresivas resulta difícil de establecer genéricamente, por lo que sólo se han podido considerar tres categorías de ilustraciones representadas en la tabla II, atendiendo a la actividad de aprendizaje que supone para los lectores.

\section{4) Relación con el texto principal}

Nos referimos aquí al tipo de relación establecido por los autores entre el texto y las imágenes. Mientras que el texto sostiene el conjunto del discurso narrativo o argumentativo, las ilustraciones muestran aspectos parciales; en otras palabras, la información incluida en las imágenes es discontinua y sólo su inclusión en el conjunto le da significado. Denominamos texto combinado con las imágenes a aquél que hace referencia explícita a una ilustración contenida en el libro, excluyendo el que se incorpora a la propia ilustración. Los textos combinados con imágenes establecen una doble codificación que debe ser correctamente interpretada en el acto de enseñanza-aprendizaje.

Las categorías establecidas dentro de esta variable aparecen en la tabla III. La figura 8 representa un ejemplo de relación sinóptica.

\section{5) Etiquetas verbales}

Las etiquetas verbales son los textos incluidos en las ilustraciones que ayudan a interpretarlas (Fig. 8). Aunque

Tabla II

Categorías establecidas respecto a la funcionalidad de las ilustraciones.

\begin{tabular}{|l|l|}
\hline Nombre & \multicolumn{1}{c|}{ Descripción } \\
\hline Inoperantes & No aportan ningún elemento utilizable, sólo cabe observarlas. \\
\hline Operativas elementales & Contienen elementos de representación universales: croquis, cotas, etc. \\
\hline Sintácticas & $\begin{array}{l}\text { Contienen elementos cuyo uso exige el conocimiento de normas específicas: vectores, } \\
\text { circuitos eléctricos, etc. }\end{array}$ \\
\hline
\end{tabular}

Tabla III

Categorías establecidas en la relación con el texto principal.

\begin{tabular}{|c|c|}
\hline Nombre & \multicolumn{1}{|c|}{ Descripción } \\
\hline Connotativa & $\begin{array}{l}\text { El texto describe los contenidos sin mencionar su correspondencia con los elementos incluidos en la } \\
\text { ilustración. Estas relaciones se suponen obvias y las establece el propio lector. }\end{array}$ \\
\hline Denotativa & $\begin{array}{l}\text { El texto establece la correspondencia entre los elementos de la ilustración y los contenidos } \\
\text { representados. Ejemplo: «La figura } x \text { muestra un dinamómetro.» }\end{array}$ \\
\hline Sinóptica & $\begin{array}{l}\text { El texto describe la correspondencia entre los elementos de la ilustración y los contenidos represen- } \\
\text { tados, yestablece además las condiciones en las cuales las relaciones entre los elementos incluidos } \\
\text { en la ilustración representan las relaciones entre los contenidos, de modo que la imagen y el texto } \\
\text { forman una unidad indivisible. }\end{array}$ \\
\hline
\end{tabular}


Figura 8

Ejemplo de categoría sinóptica. Se muestra la imagen y el texto relacionado.

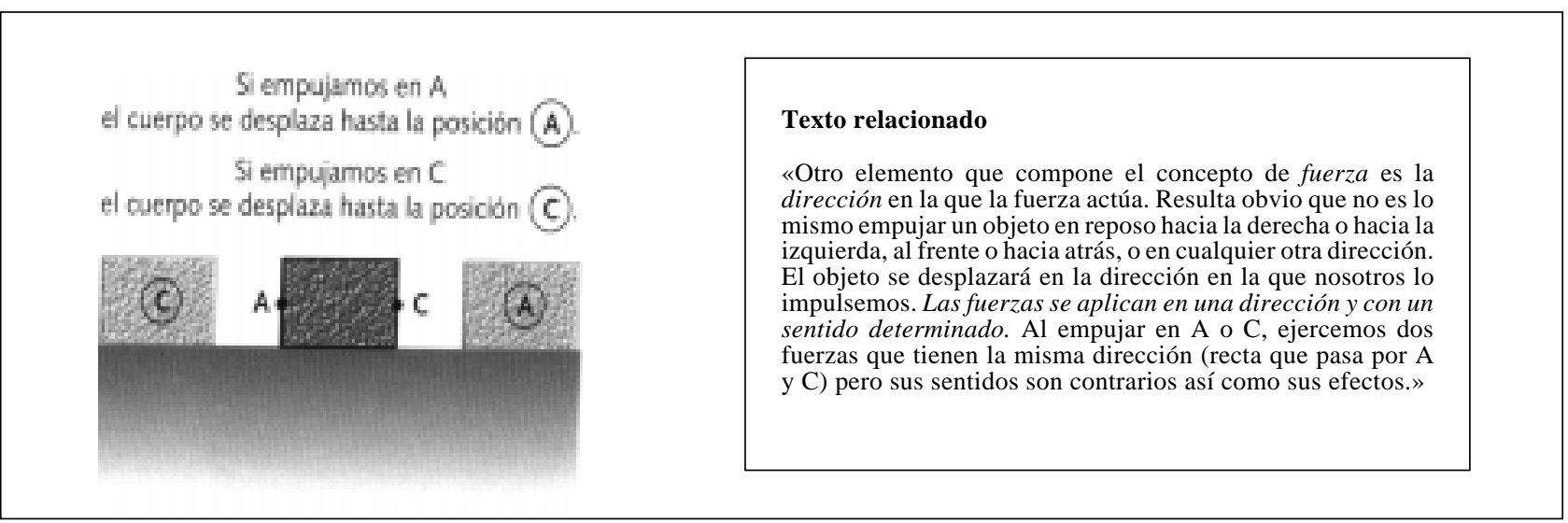

pudiera confundirse con la categoría de análisis anterior, el hecho de que el texto esté incorporado en la propia ilustración -como es ahora el caso- o ser externo a ella permite discriminar entre una ilustración autosuficiente o dependiente del texto no ilustrado, respectivamente.

En la tabla IV se recogen las posibilidades categoriales. Como se ha mencionado con anterioridad, los textos explicativos favorecen mediante un efecto de concurrencia la comprensión y aprendizaje del contenido informativo de la ilustración.

\section{6) Contenido científico que las sustenta}

Esta variable de análisis de las ilustraciones se refiere al contenido de las imágenes. Es, por tanto, específico de la temática analizada, en nuestro caso la mecánica elemental. La selección de qué contenidos son objeto de análisis en un estudio de este tipo no es casual sino que se corresponde con los objetivos de la investigación. Concretamente deseamos valorar las situaciones representadas en las ilustraciones a la luz de los resultados de la investigación educativa en el ámbito de la enseñanza de la mecánica. Así, se ha considerado relevante registrar si las imágenes incluidas en los libros representan análisis de fuerzas parciales o totales, situaciones de interacción simétricas o asimétricas, y si las fuerzas representadas actúan en la dirección del movimiento del objeto representado, en otra dirección diferente o se trata de situaciones estáticas. Como se puede ver, son tres las principales dificultades que deben superar los estudiantes, esto es, que la situación mecánica de un sistema material depende de la totalidad de las interacciones en las que se ve implicado en cada momento, que la interacción implica simultáneamente a los dos sistemas y que el movimiento es independiente de la situación dinámica. A este respecto, sería esencial que los libros contuvieran numerosos ejemplos de situaciones que mostraran todas las fuerzas que actúan sobre un objeto, que se presentaran situaciones en las que la velocidad del objeto es independiente de la resultante y otras en las que dos objetos interaccionan entre sí y experimentan efectos diferentes.

Como se refirió al principio de este trabajo, tanto desde el punto de vista de la teoría de la doble codificación de Paivio (1986) como desde los modelos mentales de

Tabla IV

Categorías establecidas en las etiquetas verbales.

\begin{tabular}{|l|l|}
\hline Nombre & \multicolumn{1}{c|}{ Descripción } \\
\hline Sin etiquetas & La ilustración no contiene ningún texto. \\
\hline Nominativas & Letras o palabras que identifican algunos elementos de la ilustración. \\
\hline Relacionales & $\begin{array}{l}\text { Textos que describen las relaciones entre los elementos de la ilustración. Un ejemplo se encontraría } \\
\text { en el dibujo de la página anterior. }\end{array}$ \\
\hline
\end{tabular}


Tabla V

Resultados acumulados obtenidos para la variable «función de la secuencia didáctica».

\begin{tabular}{|c|c|c|c|c|c|c|}
\hline \multicolumn{7}{|c|}{$\begin{array}{l}\text { Distribución de frecuencias par a las funciones: } \\
1 \text { evocación, } 2 \text { definición, } 3 \text { aplicación, } 4 \text { descripción, } 5 \text { inter pretación } \\
6 \text { problematización. }\end{array}$} \\
\hline & \multirow[b]{2}{*}{ Total } & \multirow[b]{2}{*}{ Por cent aj e } & \multicolumn{2}{|c|}{ No ilustradas } & \multicolumn{2}{|c|}{ Il ust r adas } \\
\hline & & & Tot al & Por cent aj e & Total & Por cent aj e \\
\hline 1 & 120 & 6,590 & 97 & 7,376 & 23 & 4,545 \\
\hline 2 & 667 & 36,628 & 539 & 40,989 & 128 & 25,296 \\
\hline 3 & 432 & 23,723 & 297 & 22,586 & 135 & 26,680 \\
\hline 4 & 228 & 12,521 & 166 & 12,624 & 62 & 12,253 \\
\hline 5 & 138 & 7,578 & 85 & 6,464 & 53 & 10,474 \\
\hline 6 & 236 & 12,960 & 131 & 9,962 & 105 & 20,751 \\
\hline Total & 1821 & 100,000 & 1315 & 100,000 & 506 & 100,000 \\
\hline
\end{tabular}

Johnson-Laird (1980), las imágenes producen efectos mnemónicos y estimulan la construcción de representaciones mentales que a su vez integran la representación verbal o proposicional del contenido de aprendizaje. La mecánica de Newton puede considerarse como una representación extraordinariamente simplificada del mundo que contradice prejuicios del «sentido común» y las imágenes pueden favorecer u obstaculizar esos prejuicios.

La figura 9, incluida en uno de los libros de texto analizados, trata de mostrar la aditividad de las fuerzas. La imagen puede evocar otras representaciones o modelos mentales, como, por ejemplo: que la fuerza es una acción unilateral de un objeto animado sobre otro inanimado, que para que un objeto pesado se mantenga en movimiento es necesario que una fuerza actúe continuamente sobre él, que la niña es «más fuerte» que el niño, que un armario puede ser empujado pero que no puede «empujar», etc.

Figura 9

La imagen privilegia la acción de los niños sobre el armario.

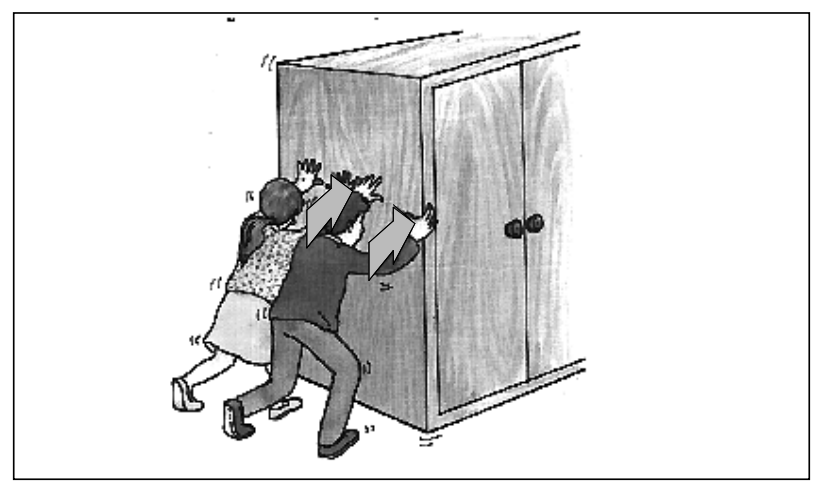

\section{Muestra de libros analizados}

Se seleccionaron siete libros de $4^{\circ}$ curso de educación secundaria obligatoria para alumnos de una edad promedio de 16 años, elegidos entre las editoriales de mayor implantación en el mercado español y cuyos años de edición estaban comprendidos entre 1993 y 1995. A ellos se añadieron otros tres libros del mismo nivel educativo, pero de ediciones más antiguas $(1963,1969$ y 1987) con el fin de disponer de una perspectiva temporal para este análisis.

Se analizaron los temas de estática y dinámica, que ocupaban en todos los casos un porcentaje de contenidos superior al $10 \%$ del total del libro de texto. En conjunto se analizaron 1.821 USD -proposiciones-, de las cuales 506 estaban ilustradas.

\section{RESULTADOS Y DISCUSIÓN}

Vamos a ir valorando los resultados obtenidos en la aplicación de las variables taxonómicas previamente descritas a la muestra de libros de texto seleccionada.

\section{Función de la unidad de secuencia didáctica -USD- en la que aparece la ilustración}

Hemos encontrado diferencias notables entre los diversos textos respecto a las secuencias didácticas y al uso de las ilustraciones. Reunimos los resultados en la tabla V para obtener una visión de conjunto. Se observa un claro predominio de la función definición seguida de la aplicación en el conjunto de las unidades de secuencia -predominio de los discursos expositivos. Si se consideran por separado aquellas USD que incluyen una ilustración, aparece una distribución más homogénea en favor de la aplicación, la definición y la problematización. 
Ocurre al contrario si sólo se tienen en cuenta los textos no ilustrados donde la definición de conceptos casi alcanza el $41 \%$.

Si consideramos un libro de texto como un documento que relata hechos, plantea preguntas, interpreta fenómenos, define conceptos, etc. y aceptamos que la ilustración viene a resaltar los aspectos más importantes de cada uno de esos momentos sin preferir unos u otros, podríamos esperar que las frecuencias relativas de las diferentes funciones que aparecen en el texto fueran similares a las que presentan los pasajes ilustrados. A esta manera de usar la ilustración la denominamos una distribución homogénea. $\mathrm{Si}$, por el contrario, aceptamos que la ilustración tiene una función muy específica, digamos, por ejemplo, que para evocar situaciones familiares o para interpretar fenómenos cotidianos, debemos esperar una distribución heterogénea.

Se realizó un ajuste mediante $X^{2}$, de los porcentajes de USD ilustradas y no ilustradas que mostró que los libros 3,5 y 10 presentan una distribución homogénea y, por el contrario, los libros 1, 2, 6 y 7 tienen una distribución heterogénea con unas diferencias significativas ( $p<0,01)$. Como ejemplo, citamos el libro núm. 1 que dedica un $50 \%$ de las secuencias a introducir conceptos mediante definiciones, mientras que sólo el 5\% de las imágenes ilustra esta función.

Una primera conclusión que puede extraerse de estos resultados es que, en cuanto a la función que puede desempeñar la imagen, no existe un patrón único a la hora de ilustrar los libros de texto y que, en todo caso, no se observa una relación entre la orientación didáctica de los textos y sus ilustraciones. Destacamos este resultado porque viene a coincidir con las quejas expresadas frecuentemente por los autores del texto de los libros en el sentido de la descoordinación entre ilustradores y autores; situación que viene propiciada por el modo de producción de los libros impuesto por las editoriales.

Incluso, cuando se manifiesta en el contenido de algunos de los libros analizados una mayor preocupación por considerar los resultados de la investigación educativa, como pueden ser los problemas de la confusión fuerzavelocidad o la simetría de las interacciones mecánicas, no se refleja esta sensibilidad en la utilización de las imágenes como ayuda para la articulación de las representaciones experimentales, mentales y simbólicas (Lemeignan y Weil-Barais, 1993).

\section{Grado de iconicidad}

Los resultados de analizar esta dimensión ponen de manifiesto que, si se agrupan las fotografías, las imágenes figurativas y las figurativas con signos superpuestos, se alcanza el $70 \%$ del total. Este último caso es mucho más frecuente $(3,75$ veces superior) al de la superposición de signos sobre dibujos esquemáticos sencillos. De cualquier modo, existen diferencias significativas de unos libros a otros.
Esta utilización masiva de las fotografías en los nuevos libros de texto, así como los dibujos figurativos con signos superpuestos no mejoran la comprensión de los textos (Jiménez, 1998), por lo que la única justificación que puede darse a este hecho, aparte de la propia evolución técnica del proceso de impresión de los libros, es la falsa creencia por parte de las editoriales de que las imágenes «atraen» a los lectores. Esta función de las imágenes es válida para el mundo de la publicidad o de la comunicación informal, donde la imagen actúa como cebo, pero en el ámbito de la enseñanza carece de justificación empírica (Levie y Lentz, 1982).

\section{Funcionalidad de las ilustraciones}

El análisis de las ilustraciones según esta variable ha permitido obtener que el $45,6 \%$ de aquéllas son inoperantes, el $22,2 \%$ operativas y el 32,2\% sintácticas.

Si nos detenemos en las ilustraciones sintácticas, observamos que casi la mitad de ellas (55 de 127) se corresponden con signos normalizados, es decir, se trata de esquemas vectoriales puros; en 58 casos de 127, los vectores se superponen sobre imágenes figurativas y sólo 15 separan completamente los planos simbólico y figurativo.

Estos últimos datos deben considerarse globalmente como un indicador más de la tendencia al realce decorativo de las ilustraciones (Fig. 10), aunque las diferencias individuales de unos libros a otros son destacables. Desde el punto de vista de la enseñanza de la física, la confusión entre realidad -plano figurativo- y conceptualización -plano simbólico- supone una dificultad añadida a los lectores, más si, como veremos a continuación, no se ofrecen demasiadas ayudas para comprender el significado de los símbolos.

\section{4 y 5 . Relaciones con el texto principal y etiquetas verbales}

Como se ha referido con anterioridad, la polisemia de las imágenes y la superficialidad con que los humanos las observamos, salvo que haya razones que nos obliguen a una inspección más rigurosa, plantean la necesidad de dirigir con cuidado su interpretación mediante el uso de palabras. Existen evidencias empíricas de que la concurrencia entre palabras e imágenes mejora el aprendizaje (Young y Wogalts, 1990; Mayer y Sims, 1994).

A tal efecto, presentaremos conjuntamente los resultados del análisis de las variables 4 y 5 , con objeto de disponer de un indicador global de la relación texto escrito - imagen para las ilustraciones de los libros de texto.

La tabla VI expone los resultados conjuntos de las variables 4 (relación con el texto principal) y 5 (etiquetas verbales). 


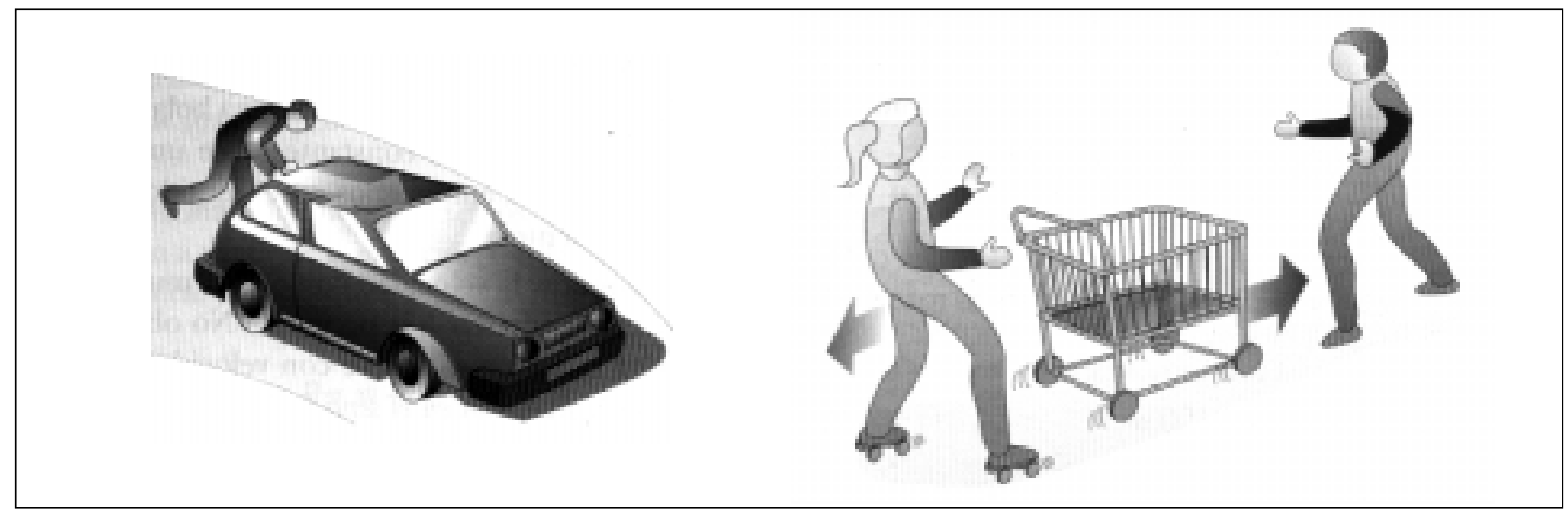

Tabla VI

Frecuencia observada para las variables «relación con el texto» $\mathrm{y}$ «etiqueta verbal» combinadas en la muestra de libros de texto.

\begin{tabular}{|c|c|c|c|c|c|}
\hline \multirow{4}{*}{$\begin{array}{l}\text { CONNOTATIVA } \\
\text { DENOTATIVA } \\
\text { SINOPTICA }\end{array}$} & $\mathrm{N}$ & NOM & REL & Total & \multirow{5}{*}{$\begin{array}{l}\mathrm{N}: \text { sin etiqueta } \\
\text { NOM: nominativa } \\
\text { REL: relacional }\end{array}$} \\
\hline & 72 & 34 & 13 & 119 & \\
\hline & 83 & 115 & 12 & 210 & \\
\hline & 11 & 48 & 40 & 99 & \\
\hline Total & 166 & 197 & 65 & 428 & \\
\hline
\end{tabular}

Estos resultados son coherentes con la idea de que, cuanto mayor es la iconicidad de una imagen, menos explicaciones se requieren para su comprensión. Sin embargo, dadas las especiales características de la mecánica elemental y las dificultades de su correcto aprendizaje, parece insuficiente que sólo 40 ilustraciones de un total de 428 alcancen el máximo nivel en la relación con un texto explicativo.

Para obtener el indicador global de la relación textoimagen hemos categorizado las dos variables en puntuaciones de 0 a 2, sumando ambas para cada ilustración, dado que tanto el texto principal como las etiquetas verbales contribuyen a descifrar las imágenes; así el nuevo índice oscilará entre 0 y 4 . El cero se corresponde con una ilustración sin etiquetas y connotada con el texto. Por el contrario, el cuatro representa una ilustración con etiquetas relacionales y que mantiene una relación sinóptica con el texto. En la figura 11 se muestra la distribución media de puntuaciones por libro.

Globalmente se puede afirmar que existe una deficiente conexión entre texto e imágenes, aunque con diferencias significativas entre los diferentes libros, a lo que habría que añadir las dificultades de interpretación ya comentadas en el análisis de la iconicidad y la funcionalidad. Como justificación de este hecho proponemos algunas causas posibles:

Figura 11

Puntuaciones medias obtenidas por cada libro.

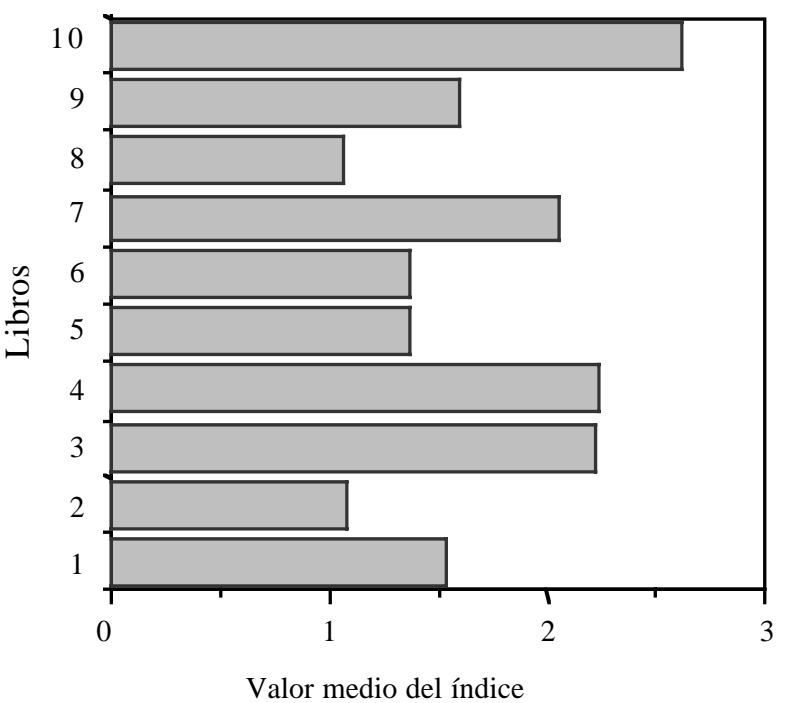

- Un exagerado optimismo respecto a la facilidad con que los lectores procesan las imágenes.

- La minusvaloración de las dificultades de interpretación de los elementos simbólicos utilizados en la representación vectorial de fuerzas. 
- La consideración de que la ilustración es un elemento superfluo que se añade al texto que no juega un papel esencial en el aprendizaje de la mecánica.

- La frecuente división del trabajo, por parte de las editoriales, entre los autores del texto y los ilustradores, junto con una deficiente coordinación entre ellos, y el consiguiente coste de producción de una ilustración bien conectada con el texto.

\section{Contenido científico que las sustenta}

El análisis del contenido de las ilustraciones presentes en los libros de texto se centró en las representaciones clave para la correcta interpretación de los fenómenos mecánicos por parte de los alumnos. Para ello se analizaron sólo las ilustraciones heterogéneas, es decir, las que superponen vectores fuerza sobre dibujos que representan objetos. Los resultados más relevantes se recogen en la figura 12.

Como puede observarse, sólo una pequeña parte de las ilustraciones $(23 \%)$ muestra todas las fuerzas que actúan, con menor frecuencia $(15 \%)$ se representa la reciprocidad $-3^{\mathrm{a}}$ ley de Newton- de las fuerzas y, finalmente, la mayoría de las ilustraciones $(54 \%)$ representan situaciones en las que la resultante de las fuerzas actuantes sobre un objeto coincide en dirección y sentido con la velocidad con que éste se desplaza.
Estos resultados desvelan importantes incoherencias entre los propósitos didácticos de los autores, materializados en los textos de sus libros, y sus ilustraciones. Por un lado, los autores son conscientes de la importancia de presentar las fuerzas como interacciones simétricas entre objetos, insisten en el concepto de resultante para determinar la situación dinámica de un objeto y presentan la asociación entre fuerza y velocidad como un obstáculo a superar. Sin embargo, las imágenes muestran análisis parciales de fuerzas, situaciones asimétricas -sólo se representa la acción sobre uno de los cuerpos-, y se privilegian aquéllas en las que las fuerzas y los movimientos coinciden. Para explicar esta aparente paradoja proponemos algunas hipótesis:

- Las representaciones donde se superponen signos vectoriales con imágenes figurativas dificultan extraordinariamente la realización de análisis de fuerzas globales que incluyan la simetría.

- Los libros de texto tratan de exponer las ideas que consideran más importantes y presentan la información muy fragmentada y jerarquizada. Como consecuencia de esta organización, cada momento de la secuencia didáctica se destina a un único fin, dejando en manos del profesorado la integración de los distintos conocimientos. Esto explicaría que una vez definido el concepto de resultante, por ejemplo, se muestren análisis muy parciales que no tienen en cuenta el total de las fuerzas que actúan sobre los objetos representados.

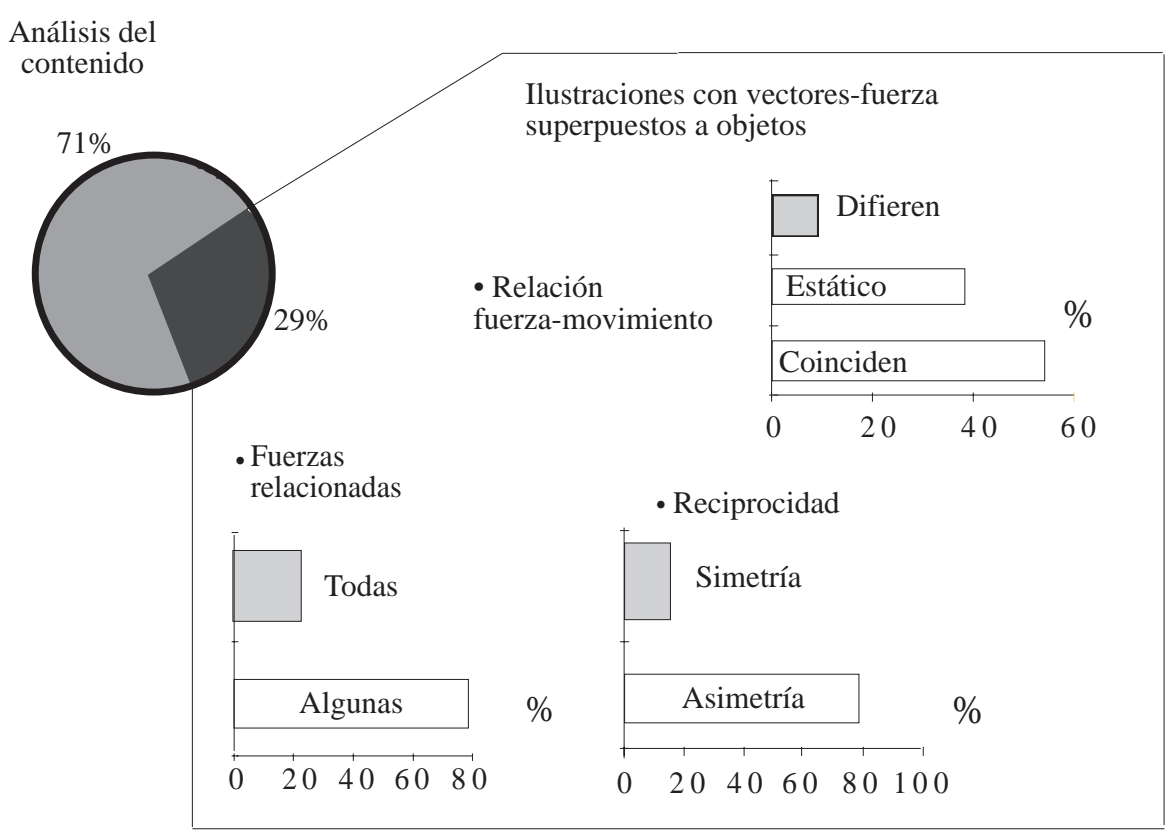


- Los autores de los libros utilizan las imágenes para reforzar y confirmar las ideas que consideran más esenciales. Para ello emplean una estrategia persuasiva que trata de proponer a los lectores mensajes sencillos o evidentes. La imagen no se utiliza como acicate para la reflexión o la duda, sino como un apoyo, en ocasiones abusivo, de una argumentación cuyo principal objetivo es convencer.

\section{CONCLUSIONES}

El trabajo que aquí acabamos de exponer nos ha permitido, en primer lugar, llamar la atención hacia una dimensión del análisis de libros de texto ciertamente descuidada, a pesar de su peso específico en el proceso de elaboración y en su resultado final tal y como se presenta ante sus potenciales clientes. En segundo lugar, hemos tratado de sintetizar las fundamentos teóricos que pretenden explicar la comprensión de las ilustraciones por los individuos, así como la función que pueden desempeñar en los textos escolares y su procesamiento por los lectores. En tercer lugar, hemos implementado una taxonomía que nos ha servido para la clasificación de las ilustraciones en libros de física y química de acuerdo con criterios sintácticos y semánticos, y estimamos que constituye un útil instrumento para el análisis y selección de tales libros por parte del profesorado.

En cuanto a los resultados más específicos de este estudio, el análisis de las ilustraciones de la muestra de libros de texto revisados desvela que, a pesar de su atractivo diseño gráfico, son numerosas las deficiencias e incoherencias que podemos encontrar en ellos.

Si consideramos los aspectos formales, debemos destacar la débil conexión existente entre las imágenes y los textos, así como la carencia de etiquetas verbales en las ilustraciones. Tal y como recogimos al comienzo de este artículo, las ilustraciones facilitan la comprensión de los textos ayudando a producir un modelo mental de la información contenida en éstos sólo si existe una correcta interpretación de las imágenes. La polisemia de la representación gráfica no garantiza que los lectores establezcan por sí mismos los vínculos necesarios entre los conceptos representados y los textos que les acompañan.

La tendencia observada hacia el embellecimiento de los libros mediante la ilustración no está justificada y añade dificultades a los lectores que se ven enfrentados a representaciones más complejas donde la proliferación de elementos distractores aumentan el riesgo de interpretaciones erróneas. Entre éstas, especialmente en el tema que ha sido elegido para el estudio, destaca la atribución de cualidades materiales a las magnitudes físicas (Viennot, 1996) mediante la equiparación de los planos de representación realista y simbólico.

Por otra parte, cabría esperar, de los equipos de profesionales que producen los libros de texto, una mayor sensibilidad hacia los resultados de las investigaciones sobre la comprensión de las imágenes en lugar de dejarse llevar por tendencias procedentes de otros ámbitos como pueda ser el publicitario. La idea ingenua de que una imagen vale por mil palabras no debiera transformar a los libros de ciencias en una colección de «cromos».

En relación con la planificación didáctica, pensamos que, igual que los autores de los textos están obligados a secuenciar sus materiales para ayudar a los alumnos a superar las dificultades previsibles de aprendizaje, los diseñadores gráficos deberían estar en condiciones de ofrecer un complemento gráfico sugerente y comprensible. En este sentido parece razonable que se tenga en cuenta la abundante literatura existente sobre las dificultades de aprendizaje de los diversos conceptos científi$\cos$.

Por último, quisiéramos apuntar algunas implicaciones educativas y sugerencias para futuras investigaciones agrupadas en los siguientes epígrafes:

- Modelos didácticos. Tomando como referencia el modelo constructivista, dada su actual influencia en la didáctica de las ciencias experimentales, sería preciso atender a las «interferencias» que sobre las concepciones de los alumnos generan las ilustraciones con que suelen acompañarse muchos tests de diagnóstico. Hay que tener en cuenta que, en estos casos, las respuestas de los alumnos pueden estar fuertemente condicionadas por su particular percepción de los códigos gráficos utilizados. Es más, dada su naturaleza polisémica, sería deseable abrir una potente línea de investigación en torno a las ideas previas que poseen los alumnos sobre las imágenes usadas habitualmente en la enseñanza de las ciencias y las posibilidades de aprendizaje a partir de estrategias explícitas de enseñanza.

- Formación del profesorado. Existen evidencias empíricas y teóricas sobre la disociación entre los códigos gráficos que manejan los profesores y los que manejan los alumnos. De ese hecho, los profesores no suelen ser conscientes, sencillamente porque no se les ha formado para ello, ya que se menosprecia la elaboración de imágenes como instrumento de modelización en la ciencia o, sencillamente, porque se deriva la responsabilidad a los «profesores de dibujo». Se hace preciso, pues, incluir actividades específicas de formación -inicial o permanente-dirigidas de un modo especial a poner de manifiesto el papel actual e histórico de las imágenes en la construcción de la ciencia y las dificultades que pueden encontrar los alumnos en su interpretación.

- Libros de texto. Hemos tenido también ocasión de comprobar, en este trabajo de investigación, las limitaciones que poseen las ilustraciones que incorporan los actuales libros de texto de ciencias en cuanto a sus posibilidades didácticas. Sería preciso elaborar un manual dirigido a los autores e ilustradores, orientándoles acerca de cómo mejorar la propia elaboración de las imágenes que utilizan y la coordinación texto-imagen, habida cuenta de la existencia de un suficiente consenso respecto a cómo abordar dichas tareas. Igualmente, el profesorado debería de disponer de una sencilla guía de evaluación de tales ilustraciones de cara a la toma de 
decisiones en la elección de editoriales para sus respectivos cursos.

- Actividades de enseñanza. Se hace evidente, por consiguiente, la conveniencia de introducir en el aula actividades específicas de enseñanza que tengan como referente las imágenes. De hecho, las posibilidades son múltiples. Señalemos algunas de ellas:

- Visión retrospectiva de las formas de representación gráfica a través de libros de texto antiguos.

- Análisis crítico de ilustraciones con distinto grado de iconicidad, separando los planos realista y simbólico.

\section{REFERENCIAS BIBLIOGRÁFICAS}

ALEXANDER, P.A. y KULIKOWICH, L.M. (1994). Learning from physics texts: a synthesis of recent research. Journal Research in Science Teaching, 31(9), pp. 895-911.

ASTER (1996). Monográfico: Images et activités scientifiques, 22.

AUSUBEL, D.P. (1982). Psicología educativa. Un punto de vista cognoscitivo. México: Trillas.

BERNAD, J.A. (1976). Guía para la valoración de los textos escolares. Barcelona: Teide.

BRUNER, J.S. GOODNOW, J.J. y AUSTIN, G.A. (1956). A study of thinking. Nueva York: Wiley.

CAMPANARIO, J.M. y OTERO, J. (2000). La comprensión de los libros de texto, en Perales, F.J. y Cañal, P. (eds.). Didáctica de las Ciencias Experimentales, pp. 323-338. Alcoy: Marfil.

CHEN, Z. (1995). Analogical transfer: from schematic pictures to problem solving. Memory \& Cognition, 23(2), pp. 255269.

DEFORGE, Y. (1991). Historia de la comunicación gráfica y diseño técnico, en Costa, J. y Moles, A. (eds.). Imagen Didáctica. Enciclopedia del Diseño, pp. 71-86. Barcelona: Ceac.

DÍAZ DE BUSTAMANTE, J. y JIMÉNEZ, M.P. (1996). ¿Ves lo que dibujas? Observando células con el microscopio. Enseñanza de las Ciencias, 14, pp. 183-194.

DONDIS, D.A. (1980). La sintaxis de la imagen. Introducción al alfabeto visual. Barcelona: Gustavo Gili, SA.

DUCHASTEL, P. (1981). Illustrations in texts: a retentional role. Programmed Learning and Educational Technology, 18 , pp. 11-15.
- Trabajo con material real y contraste con los símbolos con que es representado habitualmente.

- Incorporación al aula de las ilustraciones sobre fenómenos científicos utilizadas en la prensa escrita o en las revistas de divulgación.

- Incremento del número de problemas gráficos a resolver por los estudiantes, favoreciendo su resolución cualitativa.

- Investigación conjunta profesor/alumnos sobre posibles códigos gráficos alternativos, poniendo de manifiesto su carácter convencional.
DURÁN, A. (1987). Psicología de la publicidad y de la venta. Barcelona: Biblioteca Básica de Psicología.

ELTINGE, E.M. y ROBERTS, C.W. (1993). Linguistic content analysis: a method to measure science as inquiry in textsbooks. Journal of Research in Science Teaching, 30(1), pp. 65-83.

FESCHOTTE, D. y MOLES, A. (1991). Cómo se lee una representación gráfica compleja, en Costa, J. y Moles, A. (eds.). Imagen Didáctica. Enciclopedia del Diseño, pp. 87120. Barcelona: Ceac.

FLEIS, J.L. y COHEN, J. (1969). Large sample standard errors of Kappa and weighted Kappa. Psychological Bulletin, 72(5), pp. 323-327.

GALLEGO, A.P., GIL, D., CARRASCOSA, J. y VALLS, R. (2001). Imagen popular de la ciencia. Comunicación al I Congreso Nacional de Didácticas Específicas. Granada.

GILLESPIE, C.S. (1993). Reading graphic display: what teachers should know. Journal of Reading, 36(5), pp. 350-354.

GIORDAN, A. y VECCHI, G. (1988). Los orígenes del saber. Sevilla: Díada.

GLENBERG, A.M.y LANGSTON,W.E.(1992).Comprehension of illustrated texts: Pictures help to build mental models. Journal of Memory \& Language, 31(2), pp. 129-151.

GUTIÉRREZ, R. (1994). «Coherencia del pensamiento y causalidad. El caso de la dinámica elemental». Tesis doctoral. Madrid: Universidad Complutense.

GYSELINCK, V. y TARDIEU, H. (1994). Illustrations, mental models, and comprehension of instructional text, en Schnotz, W. y Kulhavy, R.W, (eds.). Comprehension of graphics. Advances in psychology, 108, pp. 139-152. Amsterdam: Elsevier Science B.V. 
JIMÉNEZ, J.D. (1998). «Los medios de representación gráfica en la enseñanza de la física y la química». Tesis doctoral. Universidad de Granada.

JIMÉNEZ, J.D. y PERALES, F.J. (1997). Propuesta taxonómica para un análisis de las ilustraciones en los textos de física y química, en Jiménez, R. y Wamba, A.M. (eds.). Avances en la didáctica de las ciencias experimentales, pp. 519-528. Universidad de Huelva.

JIMÉNEZ, J.D. y PERALES, F.J. (2001). Aplicación del análisis secuencial al estudio del texto escrito y de las ilustraciones de los libros de texto de física y química en la ESO. Enseñanza de las Ciencias, 19, pp. 3-19.

JOHNSON-LAIRD, P.N. (1980). Mental models in cognitive science. Cognitive Science, 4, pp. 71-115.

JOHNSON-LAIRD, P.N. (1983). Mental models: towards a cognitive Science of language, inference and consciousness. Cambridge: Harvard University Press.

KEOGH, B. y NAYLOR, S. (1998). Teaching and learning in science using concept cartoons. Primary Science Review, 51, pp. 14-16.

LARKIN, J.H. y SIMON, H.A. (1987). Why a diagram is (sometimes) worth ten thousand words. Cognitive Science, 11 , pp. 65-99.

LEMEIGNAN, G. y WEIL-BARAIS, A. (1993). Construire des concepts en physique. París: Hachette Education. Col. Didactiques.

LEVIE, W. y LENTZ, R. (1982). Effects of text illustrations: a review. Research Educational Communications and Technology Journal, 30(4), pp. 195-232.

LEVIN, J.R., ANGLIN, U.J. y CARNEY, R.N. (1987). On empirically validating functions of pictures in prose, en Willows, D.M. y Houghton, H.A. (eds.). The psychology of illustration, I, pp. 51-85. Nueva York: Springer.

MAICHLE, U. (1994). Cognitive processes in understanding line graphs, en Schnotz, W. y Kulhavy, R.W. (eds.). Comprehension of graphics. Advances in psychology, 108, pp. 207-226. Amsterdam: Elsevier Science B.V.

MAYER, R.E y SIMS, V.K. (1994). For whom is a picture worth a thousand words? Extensions of a dual-coding theory of multimedia learning. Journal of Educational Psychology, 86(3), pp. 389-400.

MAYER, R.E. (1989). Systematic thinking fostered by illustrations in scientific text. Journal of Educational Psychology, 81(2), pp. 240-246.

MAYER, R.E. (1994). Visual aids to knowledge construction. Building mental representations from pictures and words, en Schnotz, W. y Kulhavy, R.W. (eds.). Comprehension of graphics. Advances in psychology, 108, pp. 125-138. Amsterdam: Elsevier Science B.V.

MAYER, R.E. y GALLINI, J.K. (1990). When is an illustration worth ten thousand words. Journal of Educational Psychology, 82(4), pp. 715-726.

MAYER, R.E., BOVE, W., BRYMAN, A., MARS, R. y TAPANGCO, L. (1996). When less is more: Meaningful learning from visual and verbal summaries of science textbook lessons. Journal of Educational Psychology, 88 (1), pp. 6473.

McDANIEL, M.A. y WADDILL, P.J. (1994). The mnemonic benefit of pictures in text: selective enrichment for differentially skilled reader, en Schnotz, W. y Kulhavy, R.W. (eds.).
Comprehension of graphics. Advances in psychology, 108, pp. 165-184. Amsterdam: Elsevier Science B.V.

MOKROS, J.R. y TINKER, R.F. (1987). The impact of microcomputer based labs on childrens' ability to interpret graphs. Journal of Research in Science Teaching, 24(4), pp. 369-383.

MOLES, A. (1991). Pensar en línea, pensar en superficie, en Costa, J. y Moles, A. (eds.). Imagen Didáctica. Enciclopedia del Diseño, pp. 9-35. Barcelona: Ceac.

OGBORN, J. (1996). Science education and semiotics: collaborative work on explanation, imagery and rhetoric. Conferencia de la Summerschool de ESERA. Barcelona.

OSBORNE, R.J. y GILBERT, J.K. (1980). A teaching for exploring students' view of the world. Physics Education, 15 , pp. 376-379.

PAIVIO, A. (1986). Mental representations: A dual coding approach. Nueva York: Oxford University Press.

PARCERISA, A. (1996). Materiales curriculares. Cómo elaborarlos, seleccionarlos y usarlos. Barcelona: Graó. Biblioteca de Aula.

PEECK, J. (1994). Enhacing graphic-effects in instructional texts: influencing learning activities, en Schnotz, W. y Kulhavy, R.W. (eds.). Comprehension of graphics. Advances in psychology, 108, pp. 271-290. Amsterdam: Elsevier Science B.V.

PÉREZ DE EULATE, L., LLORENTE, E. y ANDRIEU, A. (1999). Las imágenes de la digestión y excreción en los textos de primaria. Enseñanza de las Ciencias, 17(2), pp. 165-178.

PFUNDT, H. y DUIT, R. (1994). Students'alternative frameworks and Science Education. Kiel: Institute for Science Education.

PIAGET, J. (1980). Biología y conocimiento, vol. b. México: Siglo XXI.

REINKING, D. (1986). Integrating graphic aids into content area instruction: The graphic information lesson. Journal of Reading, 30, pp. 146-151.

ROBINSON, D.H. y KENNETH, A.K. (1995). Visual argument: Graphic organizers are superior to outlines in improving learning from text. Journal of Educational Psychology, 87(3), pp. 455-467.

SCHNOTZ, W., PICARD, E. y HRON, A. (1993). How do successful and unsuccessful learners use texts and graphics? Learning and Instruction, 3, pp. 181-199.

SEEL, N.M. y DÖRR, G. (1994). The supplantation of mental images through graphics: instructional effects on spatial visualization skills of adults, en Schnotz,W. y Kulhavy, R.W. (eds.). Comprehension of graphics. Advances in psychology, 108, pp. 271-290. Amsterdam: Elsevier Science B.V.

SHIPSTONE, D.M., RHÖNECK, C., JUNG, L., W., KÄRRQVIST, C., DUPIN, J., JOHSUA, S. y LICHT, P. (1988). A study of students' understandig of electricity in five European countries. International Journal of Science Education, 10(3), pp. 303-316.

STONE, D.E. y GLOCK, M.D. (1981). How do young adults read directions with and without pictures? Journal of Educational Psychology, 73(3), pp. 419-426.

SWENSON, L.C. (1984). Teorías del aprendizaje. Buenos Aires: Paidós. 
VIENNOT, L. (1996). Raisonner en Physique. La part de sens commun. Bélgica: De Boeck Université.

WEIDENMANN, B. (1994). Codes of Instructional Pictures, en Schnotz, W. y Kulhavy, R.W. (eds.). Comprehension of graphics. Advances in psychology, 108, pp. 29-42. Amsterdam: Elsevier Science B.V.

WEIL-BARAIS, A. y CORROVER, D. (1993). Manuel practique de méthodologie pour la recherche en didactique. París: Association Tour 123 Siège social: Université Paris 7.

WINN, W.D. y SOLOMON, C. (1991). The effect of the rethorical structure of diagrams on the interpretation of simple sentences. Seattle: University of Washington.

WINN, W.D. (1994). Contributions of perceptual and cognitive processes to the comprehension of graphics, en Schnotz, W. y Kulhavy, R.W.(eds.). Comprehension of graphics. Advances in psychology, 108, pp. 3-28. Amsterdam: Elsevier Science B.V.
WOOLFOLK, A.E. y McCUNE, L. (1986). Psicología de la educación para profesores. Madrid: Narcea.

WORNER, C.H. y ROMERO, A. (1998). Una manera diferente de enseñar física: física y humor. Enseñanza de las Ciencias, 16, pp. 187-192.

YOUNG, S. y WOGALTS, M.S. (1990). Comprehension and memory of instructional manual warning: Conspicuous print and pictorial icons. Human Factors, 32(6), pp. 637-649.

ZINNER, H.D. (1994). Representation and processing of the spatial layout of objects with verbal and non verbal input, en Schnotz, W. y Kulhavy, R.W. (eds.). Comprehension of graphics. Advances in psychology, 108, pp. 3-28. Amsterdam: Elsevier Science B.V.

ZULEYMA, M.C. (1991). El documento persuasivo. Análisis de contenido y publicidad. Bilbao: Deusto.

[Artículo recibido en marzo de 2001 y aceptado en diciembre de 2001.] 